\title{
Modified localization coefficients for cluster processes identification: a comparative analysis (case study: the Russian rye sector)
}

\author{
O $V$ Kostenko ${ }^{1, *}$ \\ Faculty of Economics, Federal State Budgetary Educational Institution of Higher Education "Vyatka State Agricultural Academy", \\ Kirov, Russia
}

\begin{abstract}
The paper presents the results of the identification of agrarian clusters. Research is done in connection with the rye sector of Russia taken as a case study. The localization coefficients were calculated from the gross yield of winter rye grain. Two variants of calculating coefficients were compared - in proportion to the indicators of the gross regional product and employment statistics. Studies have shown that the coefficients in proportion to the gross regional product are more sensitive and allow a more subtle diagnosis of cluster processes. Localization coefficients in proportion to employment statistics are a more stringent method for identifying clusters.
\end{abstract}

\section{Introduction}

A number of recent trends in economic development have led to the formation of a new type of complex nonhierarchical systems in the economy - clusters. The processes of their formation and the sources of efficiency have been the subject of numerous studies for several decades. Over time, the academic community has formed the idea that the combination of three conditions $[1,2,3]$ creates a mechanism for the accelerated development of industries and enterprises of the cluster: -localization of economic agents and industries within a relatively small area;

-sectoral and inter-sectoral value chains within the cluster;

-sustainable network forms of interaction between cluster members.

Following this, a new direction was formed in the economic policy of states - cluster policy. In Russia, the use of the cluster approach began in the late 2000s. The active phase began in 2012, with a large-scale project of the Ministry of Economic Development of Russia to support pilot innovation clusters. Its first results became the object of close attention of researchers [4, 5]. Later, it was replaced by the project of the Ministry of Industry and Trade of Russia to support industrial clusters. Following this, cluster policy was widely developed at the regional level.

Nevertheless, the academic community continues the discussion about the relationship between the evolutionary and artificial components in the development of clusters [5]. Following foreign researchers [6], Russian scholars emphasize the need to take into account the evolutionary component in supporting clusters [7], considering the identification and diagnosis of clusters [8, 9] as the first task of regional cluster policy.

In light of this, the need for methods that are able to identify promising directions for the development of regional clusters is quite acute. Conventionally, statistical methods for identifying clusters are divided into two groups: simple and comprehensive complex methods. Comprehensive methods use a set of various indicators. Vivid examples are the methodologies of the European Cluster Observatory and Michael Porter [10]. Academic literature presents many examples of the identification of cluster processes using the structural shift method $[11,12]$. The Herfindahl-Hirschman index $[8,13]$, the concentration ratio of market share [13] and some other indicators are also used. In all methods, localization coefficients are used as one of the stages of cluster identification or as an independent method. Porter's variant of calculating coefficients according to employment statistics [7, 14] is considered classic.

The main disadvantage of the basic method is that it is applicable only forr large groups of industries, according to OKVED (Russian National Classifier of Types of Economic Activity) codes. However, agroindustrial clusters have significant specificity. Firstly, the specialization of agricultural production has bright regional differences. This is influenced by climatic and organizational-economic factors (remoteness from the areas of consumption, the shelf life of various types of agricultural raw materials and foodstuffs, historically established specialization). This study has shown that aggregated statistics are generally not able to identify localization in narrow sectors of the agro-industrial sector [15]. Secondly, to gain "critical mass", the raw material base of agrarian clusters may cover the

* Corresponding author: kostenko_ov@,vgsha.info 


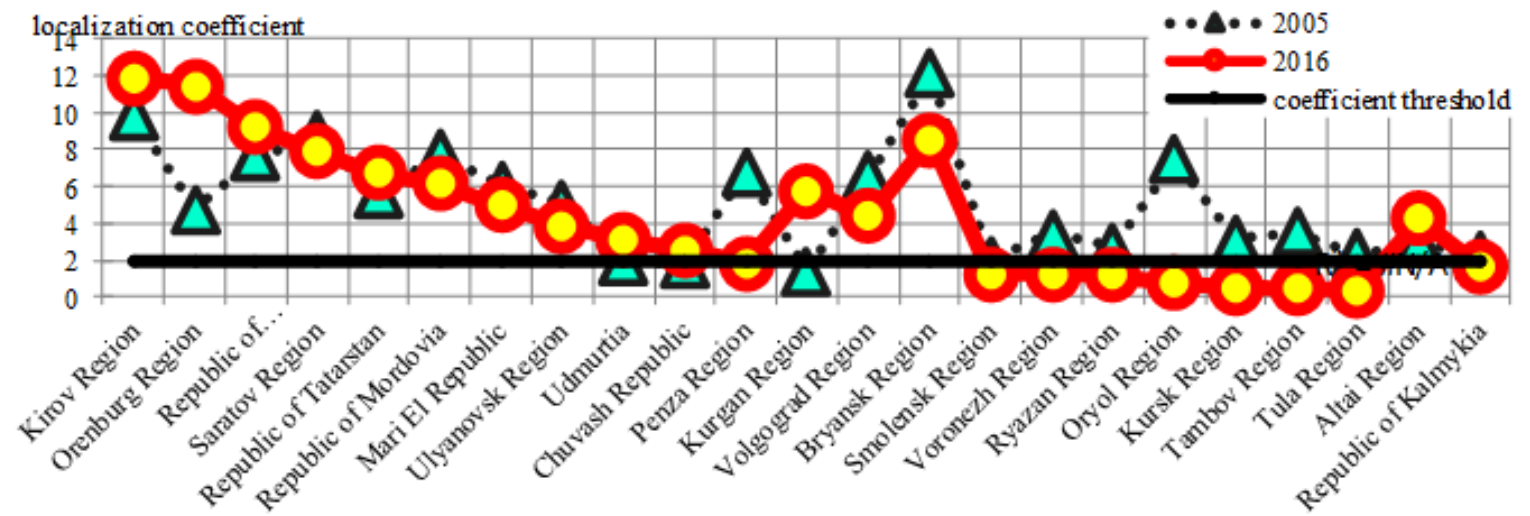

Fig. 1. Localization coefficients of the gross harvest of winter rye in proportion to the gross regional product.

territories of several neighboring regions, causing a tendency to form interregional clusters [16].

To identify localization in narrow sectors of the agrarian economy, one can use the so-called modified localization coefficients. Unlike the base case, they are calculated for various indicators. So, Kolchinskaya [17] used the indicators of the volume of goods shipped, the number of organizations, the net financial result, investment, labor productivity, and profitability to analyze the localization of sectors of St. Petersburg. Prokopiev [18] carried out calculations for the forest sector of Russia in terms of tax indicators - collection of regional taxes and separate collections of property tax. Golovin [19] by the example of the Republic of Mari El used the indicators of turnover, labor productivity, and the number of enterprises.

The essential element of the use of localization coefficients is the choice of the threshold value of an indicator. The threshold 1.0 proposed by Porter is used most frequently. However, a slight and unstable excess of 1.0 threshold can hardly be an indicator of the development of cluster processes. A number of researchers use higher thresholds: Bergman and Feser [20] - 1.25; Danko and Kutsenko [21] - 2.0.

Objective of the study is to compare the variants of modified localization coefficients and identify their sensitivity taking the rye sector of Russia as the case study.

\section{Methodology}

Theoretical and methodological basis is works on the theory of clusters and methods for their identification. The modified localization coefficients were used, which were calculated for agricultural production in physical terms (gross grain harvest of winter rye) in proportion to two indicators: the gross regional product and the average annual number of employees. A high threshold of localization coefficient equaling 2.0 was selected. For agriculture, this is more relevant, since the industry is characterized by significant fluctuations in production over the years, especially in crop production (highyielding and lean years). The information base for the study was the data from the Central Statistical Database of the Federal State Statistics Service of Russia.

\section{Results and Discussion}

During the study of cluster processes in the case study of the rye sector of Russia [22], a group of compactly located regions of the Volga Federal District with high localization coefficients (steadily above 2.0) was identified. At the first stage, modified coefficients of the gross harvest of rye grain were used in relation to the size of the gross regional product. The analysis of indicators over time is presented in Figure 1. The

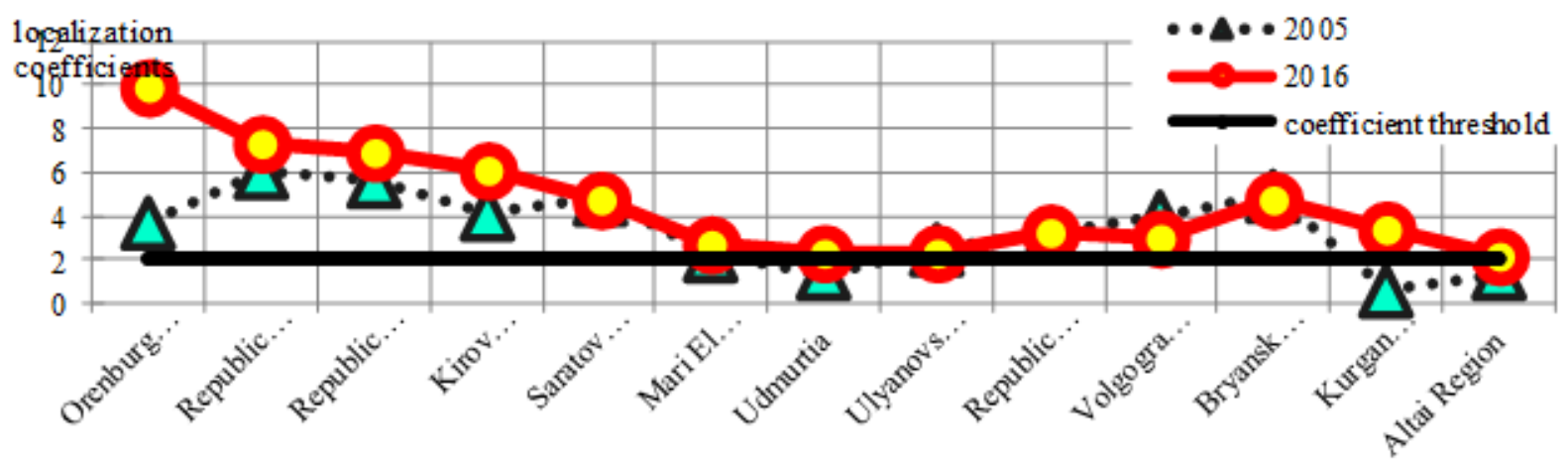

Fig. 2. Localization coefficients of the gross harvest of winter rye in proportion to the average annual number of employees. 


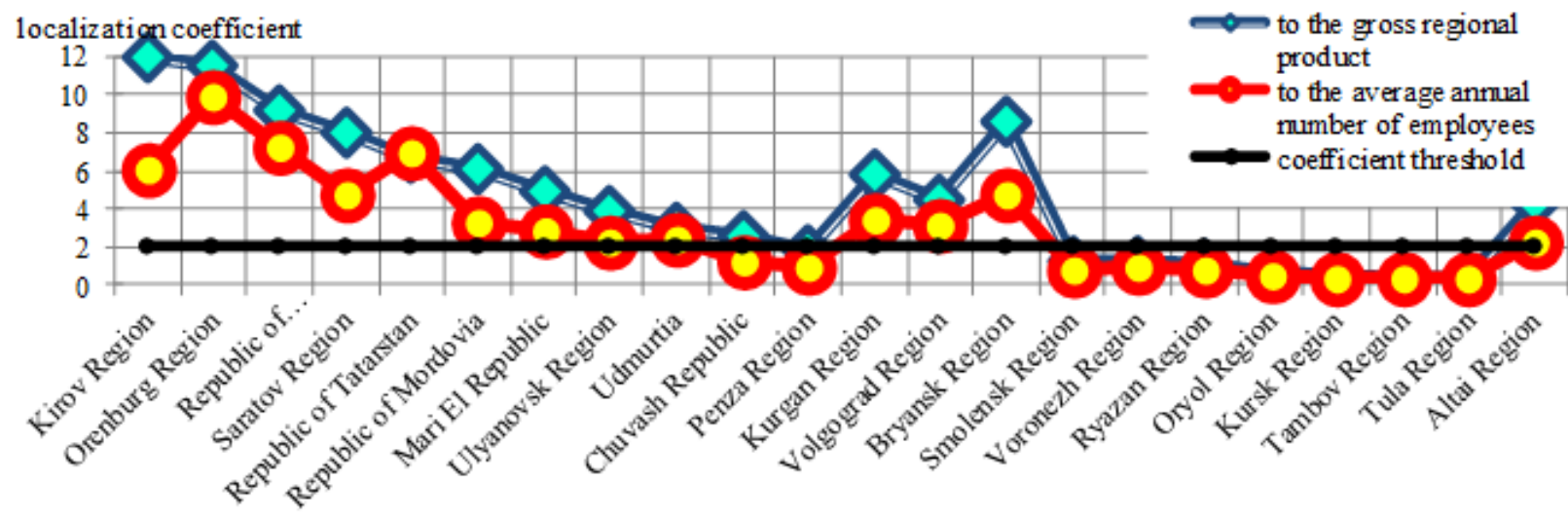

Fig. 3. Comparison of the gross harvest of winter rye in proportion to the average annual number of employees.

diagram shows regions with localization coefficients above threshold 2.0 for the period of 2005-2016.

In this variant, the localization coefficient showed high sensitivity. One can see not only a group of the Volga regions (in the diagram, from Kirov to Penza Regions) with the neighboring Kurgan and Volgograd Regions adjacent to it. There was also the "disappearing" localization of rye in the Central Federal District (from Bryansk to Tula Regions). All these regions have favorable climatic conditions for the cultivation of winter rye ("rye belt", continuing in the territory of Belarus). However, under the influence of a number of external factors, the central regions are changing the specialization and composition of the crop production sectors.

However, the calculation of localization factors on the basis of cost indicators has several disadvantages. In particular, distortions of the real scale of economic activity are possible, when companies can record revenue where it is not actually received. Calculation by employment indicators gives a higher degree of reliability.

At the second stage, the localization coefficients for the gross harvest of rye grain were calculated in relation to the average annual number of people employed in the economy (Figure 2).
This variant of modified localization coefficients turned out to be more rigid. Nevertheless, this method revealed a stable localization in the composition of the nine main rye regions of the Volga (only their ranked range changed, the coefficient in the Kirov Region greatly subsided), as well as other regions with a high level of localization - the Bryansk, Volgograd, and Kurgan Regions, Altai Region. However, the disappearing localization of the central regions of Russia was not identified even in retrospect.

Now, the authors will try to compare both versions of the localization coefficient for the same periods. The data for 2005 and 2016 are presented in Figures. 3 and 4, respectively.

The analysis allows formulating several conclusions: -both variants of the coefficients reveal almost the same tendencies of localization change by region (with the exception, perhaps, of the Kirov and Saratov Regions, the Republic of Mari El);

-the level of the coefficient by the gross regional product is slightly higher than by the employment rate; -calculation of localization by employment gives noticeably more "smoothed" results;

-according to data for 2005, the cut-off threshold 2.0 worked somewhat harder. For 2016, the results of assigning regions to groups with high or low localization

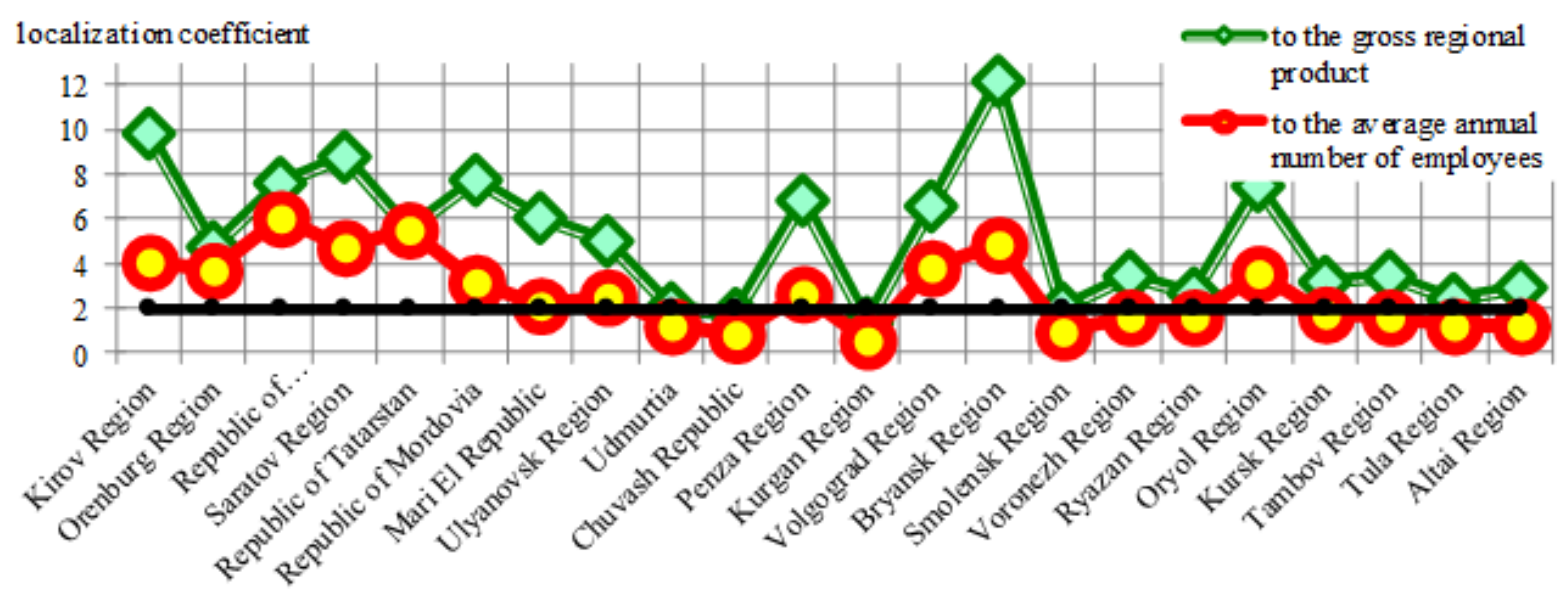

Fig. 4. Comparison of the localization coefficients of the gross harvest of winter rye, 2005. 
Table 1. Reduction of winter rye localization coefficients in Central Federal District, 2004-2016*.

\begin{tabular}{|c|c|c|c|c|c|c|c|c|c|c|c|c|c|}
\hline Regions & 2004 & 2005 & 2006 & 2007 & 2008 & 2009 & 2010 & 2011 & 2012 & 2013 & 2014 & 2015 & 2016 \\
\hline \begin{tabular}{|l} 
Bryansk \\
Region
\end{tabular} & 16.0 & 12.1 & 10.7 & 9.0 & 11.1 & 10.0 & 13.1 & 10.3 & 11.3 & 6.8 & 7.4 & 8.5 & 8.6 \\
\hline Oryol Region & 9.4 & 7.4 & 6.0 & 4.7 & 6.9 & 5.9 & 8.0 & 2.4 & 4.2 & 2.6 & 2.1 & 0.9 & 0.7 \\
\hline Kursk Region & 3.5 & 3.1 & 3.7 & 3.2 & 4.1 & 3.4 & 2.9 & 2.3 & 2.2 & 1.8 & 1.1 & 0.9 & 0.5 \\
\hline $\begin{array}{l}\text { Voronezh } \\
\text { Region }\end{array}$ & 3.8 & 3.4 & 2.7 & 2.7 & 3.9 & 2.2 & 1.6 & 1.6 & 2.7 & 2.0 & 1.5 & 1.4 & 1.2 \\
\hline \begin{tabular}{|l|}
$\begin{array}{l}\text { Tambov } \\
\text { Region }\end{array}$ \\
\end{tabular} & 3.7 & 3.5 & 4.6 & 2.8 & 3.7 & 1.9 & 1.7 & 1.6 & 2.7 & 2.2 & 1.3 & 0.8 & 0.4 \\
\hline Ryazan Region & 2.9 & 2.7 & 2.5 & 2.4 & 1.9 & 1.4 & 1.7 & 1.3 & 1.9 & 1.5 & 0.8 & 1.6 & 1.2 \\
\hline Tula Region & 2.5 & 2.4 & 1.5 & 1.9 & 2.0 & 1.3 & 1.4 & 0.8 & 1.3 & 0.8 & 0.6 & 0.6 & 0.4 \\
\hline $\begin{array}{l}\text { Smolensk } \\
\text { Region }\end{array}$ & 2.8 & 2.0 & 1.3 & 1.4 & 1.6 & 1.2 & 1.5 & 1.3 & 2.3 & 0.9 & 1.1 & 1.2 & 1.2 \\
\hline
\end{tabular}

turned out to be similar.

The markedly better sensitivity of the gross regional product coefficient can be demonstrated by the example of the gradual withdrawal of the central regions of Russia from rye commodity production (Table 1).

To date, the high localization of rye has been preserved only in the Bryansk Region bordering on Belarus.

\section{Conclusions}

Agrarian clusters have some specific features of formation. Their sectoral specialization has bright natural and organizational-economic factors. In this regard, cluster identification requires an analysis of localization in the context of narrow branches of the agro-industrial sector. To this end, it is recommended to apply modified localization coefficients, which can be calculated on the basis of gross agricultural output.

A comparison of two variants of localization coefficients using the example of the rye sector of Russia showed that the coefficients, calculated in proportion to the gross regional product, are more sensitive and allow for more sophisticated diagnostics of cluster processes. Unlike them, localization coefficients in proportion to employment statistics are a more rigid method for identifying clusters.

\section{References}

[1] M.E. Porter, C.H.M. Ketels, Clusters and industrial districts: common roots, different perspectives, in A Handbook of Industrial Districts, Cheltenham: Edward Elgar, 172-186 (2009). DOI: 10.4337/9781781007808.00024.

[2] L.S. Markov, M.V. Petukhova, K.Y. Ivanova, The cluster policy organizational structures, The Journal of the New Economic Association, 3, 140-152 (2015).

[3] L.A. Aleksandrova and O.V. Matveeva, Institutional approach in cluster research, The Agrarian Scientific Journal, 10, 65-69 (2014).
[4] E. Kutsenko, Pilot innovative territorial clusters in Russia: a sustainable development model, Foresight Russia, 9, 1, 32-55 (2015).

[5] S. Zemtsov, V. Barinova, A. Pankratov, E. Kutsenko, Potential high-tech clusters in Russian regions: from current policy to new growth areas, Foresight and STI Governance, 10, 3, 34-52 (2016). DOI: 10 17323/1995-459X.2016.3.34.52.

[6] O. Solwell, Four dimensions of clusters, in Clusters: World, Russia, regions (2013) [Electronic resource]. Available at: http://www.iregions.org/media/views.php? ID $=10227$.

[7] S.M. Rastvortseva, N.A. Cherepovskaya, Identification and assessment of regional clusters, Economy of Region, 4, 123-133 (2013).

[8] T.Yu. Kovaleva, Diagnostics of clusters as a guideline for the state policy of territorial development, Journal of Economic Theory, 4, 9195 (2011).

[9] V.A. Golovin, Analysis of factors and development potential of economic clusters by economic activities in Mari El Republic, Economy of Region, 13, 4, 1068-1079 (2017). DOI: $10 / 17059 / 2017-4-8$.

[10] M. Porter, The Economic performance of regions, Regional Studies, 37, 6-7, 549-578 (August/October 2003).

[11] G. Baturin, D.D. Korotkova, M.A. Pervukhin, Identification of industrial clusters in the Primorye Territory, Fundamental Research, 11, 6, 1145-1148 (2015).

[12] J. Stejskal, Comparison of often applied methods for industrial cluster identification, in International Conference on Development, Energy, Environmental, Economics (DEEE '10) Puerto De La Cruz, Tenerife: WSEAS Press, 282286 (2010).

[13] D.L. Napolskikh, Trends and promising models forming industrial clusters in the Russian Federation, Economic and Social Changes: Facts, Trends, Forecast, 10, 6, 248-263 (2017). 
[14] M. Vinokurova, Competitiveness and potential of clustering industries of the Irkutsk Region, ECO, 12, 73-91 (2006).

[15] O.V. Kostenko, Identifying agroindustrial clusters by using location quotients, Problems of Theory and Practice of Management, 5, 88-93 (2017).

[16] O.V. Kostenko, Are Russian agro-industrial clusters an idea or reality?, Economics: Yesterday, Today and Tomorrow, 4, 35-46 (2016).

[17] E.E. Kolchinskaya, Creating clusters on the basis of the processing industries of St Petersburg - an approach to identifying promising industries through localization coefficients, North-West Economics: Problems and Development Prospects, 1, 10 (2011).

[18] E.A. Prokopiev, To the issue on data selection for regional specialization identification, Drucker Herald, 4, 236-245 (2015).

[19] V.A. Golovin, Methodolodical approaches to quantitative evaluation of regional economic clusters, Bulletin of the Nizhny Novgorod University named after N. I. Lobachevsky, Series: Social Sciences, 4, 17-26 (2016).

[20] E. Bergman, E. Feser, Industrial and Regional Clusters: Concepts and Comparative Applications West Virginia University [Electronic resource]. Available at: http://www.rri.wvu.edu/WebBook/BergmanFeser/contents.htm.

[21] G.V. Danko, E.S. Kutsenko, The main approaches to the identification of clusters in the regional economy, Problems of the Modern Economy, 1，41，248-254 (2012) [Electronic resource]. Available at: http:/www.meconomy.ru/art.php?nArtId=3960.

[22] O.V. Kostenko, Localization of winter rye cultivation in the Volga Federal District as a raw material zone of rye cluster, Economics: Yesterday, Today and Tomorrow, 7, 263-276 (2016). 